\title{
The Traumas of Displacement
}

\author{
David G. Hutton
}

Most refugees, regardless of geographical and historical circumstance, must cope with extreme and frequently life threatening conditions. In the past decade, much has been written of the Vietnamese Boat People and their harrowing experiences of flight. More recently have come the reports of civilian massacres and "ethnic cleansing" in the Balkans. In Africa, where famine is as much an enemy as guns and bullets, the death toll continues to rise.

An assessment was carried out on the conditions of the displacement and flight of Ethiopian, Laotian, Vietnamese, Chilean and Salvadorean refugees resettled in Winnipeg. Of the 115 refugees surveyed, fully 90 percent believed that their lives had been at least "sometimes" in danger while living in their country. Almost 60 percent reported that were "frequently" or "always" in danger. Many, either prior to or during their flight, had been imprisoned (32 percent), physically assaulted (30 percent), and/or attacked by a government or rebel force (31 percent). Over one-third reported of a death (44 percent), abduction or disappearance (37 percent) of an immediate family member, relative, or close friend.

Just over two-thirds of the sample rated the conditions of their country prior to their departure as " somewhat" to "extremely" adverse. The most cited reasons for flight, of which at least one was reported by 83 percent of the refugees, included the need to secure personal safety ( 40 percent), the desire to attain personal freedom ( 35 percent), and the wish to escape government persecution or harassment (33 percent). Only 14 percent of the refugees had sought resettlement for the purpose of bettering their own lives.

Approximately two-thirds of the sample, and 88 percent of the Ethiopian and Asian refugees, fled their countries "illegally" - the governments neither knew of nor consented to their leaving. Conditions encoun- tered during this period were rated as "very" or "extremely" adverse by 45 percent of the refugees. Of those who fled overland or by sea, again predominantly Ethiopian and Asian in origin, 73 percent believed that their lives had been "frequently" or "always" in danger. Exactly one-quarter of these refugees had lacked adequate transportation while 30 percent had gone without food and/or water. Attacks,

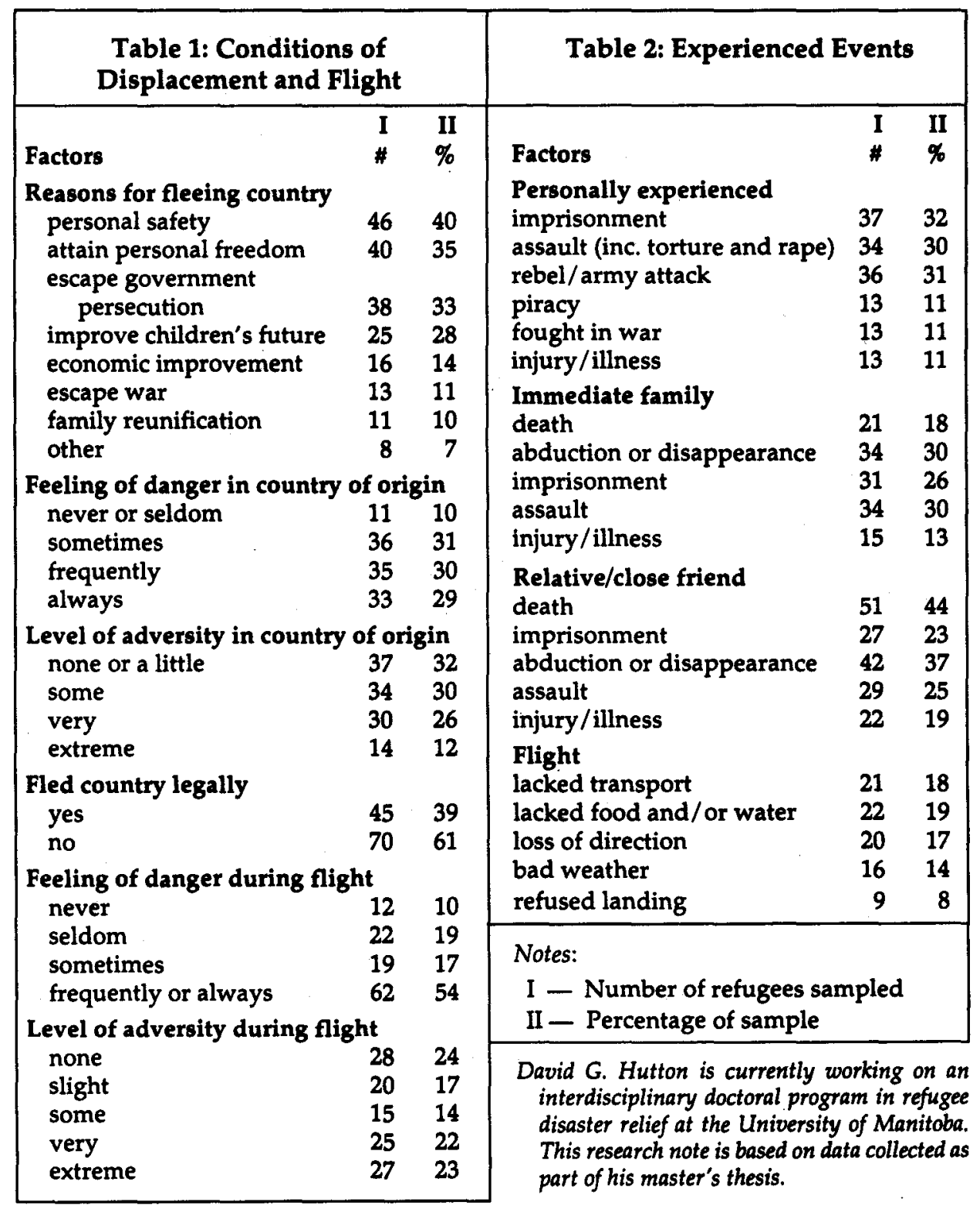

by pirates or a military force, were reported by 31 percent of the refugees.

The data clearly reveals a common experience of pain and adversity among refugees. Practitioners, as well as researchers, must be aware of both the past which many refugees bring to resettlement as well as the possible impact of trauma upon their capacity to adapt to the demands of involuntary migration. 